\title{
Preliminary Physico-Chemical Investigation of Local Binding Agents in Mineral Salt Licks Production for Ruminants
}

\author{
Adegun Maria Kikelomo \\ Department of Animal Production and Health Sciences, Ekiti State University, P M B 5363, Ado- Ekiti. Nigeria
}

\begin{abstract}
Investigation of the minerals, anti-nutrients as well as compactness and hardness of mineral saltlicks produced using cement, termite mound and clay mud as binders were compared with a commercial lick in a completely randomized design of four treatments and three replicates each was conducted.

The sodium content of commercial salt lick (treatment 1)

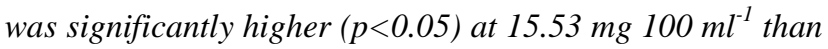
the sodium content of all other treatments. The values of zinc, copper, chromium, magnesium, iron, manganese, potassium, and cobalt were increased significantly ( $p<0.05$ ) in treatment 2 (termite mound, bone meal and common salt) at $0.08,0.25,0.25,0.65,0.26,0.23,175.93,0.19 \mathrm{mg} 100 \mathrm{ml}^{-}$

${ }^{1}$ respectively. Significantly higher but increasing $(p<0.05)$ values of calcium were obtained for treatment 2, 3(cement, bone meal and salt) and 4 (clay mud, bone meal and salt) while commercial lick's calcium content was $13.0 \mathrm{mg}$ $100 \mathrm{ml}^{-1}$.
\end{abstract}

The composition of tannin, phenol and phytate $(1.24 \mathrm{mg}$

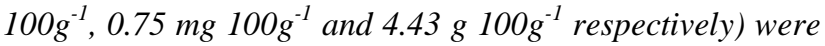
increased significantly $(p<0.05)$ in treatment 2 , while treatment 1 had lowest values of tannin and phytate

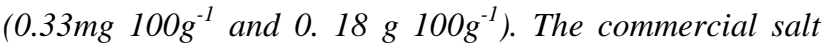
block was the most compact and hardest of the mineral salt blocks while the salt block produced using cement, termite mound and clay mud as binders had good consistencies two weeks after demoulding.

Mineral salt licks produced using different binder agents possessed higher mineral contents except sodium than commercial salt licks and have considerable binding property.

Keywords- Geophagy, binders, licks, ruminants, physicochemical.

\section{INTRODUCTION}

Grazing animals depend on range forages to meet all their nutritional requirements including macro and micro minerals such as calcium, potassium, sodium, chlorine, phosphorus, iodine, sulphur, selenium, manganese, molybdenum etc. The forage resources usually consumed by these animals in the tropics are characterized by low digestibility, energy, crude protein and poor availability of minerals and vitamins $[1,2]$.Under circumstances where no compound feed is offered, for example in breeding young stock and lactating animals or in marginal grazing areas, the need for mineral supplementation becomes very important. When forages or feed sources are deficient in minerals, ruminants seek alternative sources such as eating woods, nylon, paper, fence chewing, debarking trees, and licking each other etc. [3]. In order to prevent these habits and to supply the needed minerals to cattle, sheep and goats, there is need to supplement their diet with mineral (salt) lick.

Grazing livestock from tropical countries although depend almost exclusively upon forage for their mineral requirements, often do not receive mineral supplementation except for common salt [4]. This could be as a result of low economic power or belief of the farmers that ruminants require only common salt as a source of minerals. The supposition that the use of salt licks is attributable to only the need for sodium has been refuted by results from analyses of some natural lick soils showing low sodium contents and the presence of other important elements. Ruminants require elements such as magnesium [5], buffering compounds such as carbonates [6], and binding agents such as clays [7]. Studies from these authors also suggest multiple reasons for mineral lick needs [4-7].

Salt licks can be naturally occurring in salty mineral deposits where animals especially those in the wild trek long distances to access and they contain sodium, calcium, iron, phosphorous, zinc, and trace elements $[6,8]$. Variation in natural salt lick composition presupposes that lick may serve multiple functions for different species and sexes at different times of the year [6]. 
Mineral Salt licks or blocks for domestic ruminants can be produced from readily available and cheap sources to provide the animals with minerals needed for proper functioning of the body. They are produced using common salt (sodium with chlorine often added iodine) and other mineral sources in the manufacturing process. Sources of minerals for manufacture of mineral blocks include bone, egg shell, oyster shell and common salt. Termite mound, red mud, cement and other materials also contain calcium, silica and other minerals and can serve as binders to ensure hardness and compactness of the block. Termite mound and red mud are readily available in the rainforest area of Nigeria at no cost. However, cement seems to be an effective binder and easily available especially in the process of multi-nutrient block manufacture [9, 10], but, there are some concerns over its negative health effects and its high cost. Cattle farmers in Nigeria and especially in the southwest rely solely on commercial salt licks which may be expensive and may not contain other minerals in appreciable amount other than common salt.

There is the need to estimate the physico-chemical composition of mineral salt licks produced using locally sourced ingredients as binders in South-western Nigeria. To the best of our knowledge, literature on such study is very scanty in Nigeria. This study was undertaken to compare the physicochemical characteristics of mineral salt licks produced using different binders with a commercial salt lick.

\section{MATERIALS AND METHODS}

\subsection{Experimental Site}

The experiment was conducted at the Small Ruminants Unit of the Teaching and Research Farm, Ekiti State University, Ado-Ekiti, South Western Nigeria. Ado-Ekiti lies between latitude $07^{0} 37^{\prime} 15^{\prime \prime} \mathrm{N}$ and longitude $05^{\circ} 13^{\prime} 17^{\prime \prime} \mathrm{E}$ with an average relative humidity of $72 \%$. It experiences a tropical climate with a temperature range of $20-28^{\circ} \mathrm{C}$ and a bimodal rainfall distribution between April and October with peaks in June and September and a break in August. Dry season is between November and March. The average precipitation in this area is $1367 \mathrm{~mm}$.

\subsection{Ingredients}

Clay mud and termite mound were sourced from the soil in the Teaching and Research Farm while cement and common salt were purchased from the market. Bone was obtained from the abattoir at the Cattle Slaughtering Unit of the Teaching and Research Farm, and burned until it becomes white and then crushed in a mortar. The crushed bone meal was milled in a hammer mill to obtain a finely ground product.

\subsection{Experimental Design}

The experimental design was a completely randomized design with 4 treatments and 3 replicates.

Treatment 1 - Commercial salt lick (control)

Treatment 2 - Mineral salt lick made from termite mound, bone meal and common salt.

Treatment 3 - Mineral salt lick made from cement, bone meal and common salt.

Treatment 4 - Mineral salt lick made from clay mud, bone meal and common salt.

2.4. Mineral Salt Lick Preparation

The binders (cement, termite mound and clay mud) were separately dissolved in water to form a paste.

In treatments 2, 3 and 4, the proportion of each of the ingredients were- bone meal: salt: termite mound/ red mud/ cement $(4: 2: 1)$. The ingredients were mixed and stirred together according to each treatment to obtain a homogeneous mixture.

The mixture was poured into $5 \mathrm{~kg}$ capacity aluminum container mould, then pressed manually using hand to form blocks. The surface of the mould was covered with polythene sheets to facilitate de-moulding and clearing of the surface. The blocks were removed carefully and dried for one week under shade, and another week in the sun until they were hard.

\subsection{Physical Properties of the Salt Licks}

Hardness and compactness of the blocks were tested after de-moulding, at one week and two weeks by 3 persons independently assessing hardness on the scale: soft, medium and good, Hardness was determined by pressing with hand while compactness by the easiness of break by hand depicted by the scale: loose, slightly loose and firm.

2.6. Chemical Analysis of the Salt Licks

Triplicate samples were obtained from moulded mineral salt licks and a commercial salt lick and analysed for minerals and anti-nutritional factors. Mineral composition was determined by dry- ashing $1 \mathrm{~g}$ each of the samples at $550^{\circ} \mathrm{C}$ in a furnace, and dissolving the ash in $10 \% \mathrm{HCl}$ and filtered [11]. Sodium $(\mathrm{Na})$ and potassium $(\mathrm{K})$ were determined by flame photometer while atomic absorption spectrometer (AAS) was used to determine the other minerals. Phytin was extracted and precipitated using the method of Wheeler and Ferrel[12], Tannin content by the method of Makkar and Goodchild[13], Oxalate content was determined using the procedure of Yan et al.[14]. Saponin was assayed by the method described by Obadoni and Ochuko[15] while Alkaloid was obtained by Harbone[16] method. A pH 
meter with combined glass electrode was used to determine the $\mathrm{pH}$ of the mineral salt licks.

2.7. Data Analysis

All data obtained were analysed using one way ANOVA with Minitab 8.1 version package. Significant differences were separated using the DMRT.

\section{RESULTS}

Minerals and $\mathrm{pH}$ composition of commercial salt lick and mineral licks produced using different binders are shown in TABLE 1. From the Table, there were significant differences in all the parameters measured. The sodium content of commercial salt lick (treatment 1) was significantly higher $(\mathrm{p}<0.05)$ at $15.53 \mathrm{mg} 100 \mathrm{ml}^{-1}$ than the sodium content of all other treatments. Sodium contents of bone meal, termite mound and salt (treatment 2), bone meal, cement and salt (treatment 3 ) or bone meal, clay mud and salt (treatment 4$)$ were significantly different $(\mathrm{p}<0.05)$ at $6.49,4.85$ and $5.22 \mathrm{mg} \mathrm{ml}^{-1} 0^{-1}$ respectively with treatment 2 recording highest value. The values of zinc, copper, chromium, magnesium, iron, manganese, potassium, cobalt and lead were increased significantly $(\mathrm{p}<0.05)$ in treatment 2 (termite mound and bone meal) at $0.08,0.25,0.25,0.65$,

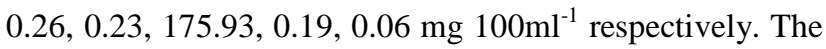
composition of calcium, magnesium, potassium, phosphorus, and cobalt were reduced significantly $(\mathrm{p}<0.05)$ in treatment 1 (commercial salt lick) with values of 13.0,

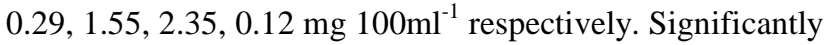

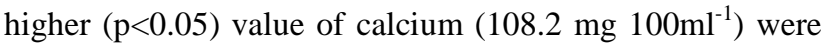
obtained for treatment 3 while treatment 1 had the lowest calcium content of $13.0 \mathrm{mg} 100 \mathrm{ml}^{-1}$. Phosphorus was increased significantly $(\mathrm{p}<0.05)$ in treatment 2 at $175.93 \mathrm{mg}$ $100 \mathrm{ml}^{-1}$. There were no significant differences $(\mathrm{p}>0.05)$ among the means of zinc, copper, chromium, iron and manganese in treatments 1,3 , and 4 with values ranging

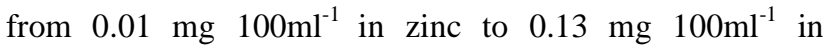
chromium. The $\mathrm{pH}$ composition of the mineral licks was raised significantly $(\mathrm{p}<0.05)$ at 10.83 in treatment 3 while the lowest value of 7.84 was obtained from treatment 4 .

Table.1: Mineral and pH analysis of mineral salt licks produced using different binders $\left(\mathrm{mg}^{\left.100 m l^{-1}\right)}\right.$

\begin{tabular}{lllll}
\hline \multicolumn{1}{c}{ Parameters } & \multicolumn{4}{c}{ TREATMENT } \\
\hline Zinc & \multicolumn{1}{c}{$\mathbf{1}$} & \multicolumn{1}{c}{$\mathbf{2}$} & \multicolumn{1}{c}{$\mathbf{3}$} & \multicolumn{1}{c}{$\mathbf{4}$} \\
Copper & $0.01^{\mathrm{b}} \pm 0.00$ & $0.08^{\mathrm{a}} \pm 0.00$ & $0.01^{\mathrm{b}} \pm 0.00$ & $0.01^{\mathrm{b}} \pm 0.00$ \\
Chromium & $0.12^{\mathrm{c}} \pm 0.01$ & $0.25^{\mathrm{a}} \pm 0.01$ & $0.11^{\mathrm{c}} \pm 0.01$ & $0.11^{\mathrm{c}} \pm 0.01$ \\
Calcium & $0.13^{\mathrm{b}} \pm 0.00$ & $0.25^{\mathrm{a}} \pm 0.00$ & $0.15^{\mathrm{b}} \pm 0.01$ & $0.13^{\mathrm{b}} \pm 0.01$ \\
Magnesium & $13.0^{\mathrm{d}} \pm 0.10$ & $79.47^{\mathrm{c}} \pm 0.58$ & $108.02^{\mathrm{a}} \pm 0.01$ & $94.36^{\mathrm{b}} \pm 0.57$ \\
Iron & $0.29^{\mathrm{c}} \pm 0.11$ & $0.65^{\mathrm{a}} \pm 0.01$ & $0.35^{\mathrm{b}} \pm 0.01$ & $0.34^{\mathrm{b}} \pm 0.01$ \\
Manganese & $0.16^{\mathrm{b}} \pm 0.01$ & $0.26^{\mathrm{a}} \pm 0.01$ & $0.15^{\mathrm{b}} \pm 0.01$ & $0.15^{\mathrm{b}} \pm 0.01$ \\
Sodium & $0.12^{\mathrm{b}} \pm 0.01$ & $0.23^{\mathrm{a}} \pm 0.0$ & $0.13^{\mathrm{b}} \pm 0.01$ & $0.13^{\mathrm{b}} \pm 0.01$ \\
Potassium & $15.53^{\mathrm{a}} \pm 0.06$ & $6.49^{\mathrm{b}} \pm 0.01$ & $4.85^{\mathrm{d}} \pm 0.06$ & $5.22^{\mathrm{c}} \pm 0.10$ \\
Phosphorus & $1.55^{\mathrm{d}} \pm 0.04$ & $1.79^{\mathrm{b}} \pm 0.01$ & $1.68^{\mathrm{c}} \pm 0.01$ & $1.79^{\mathrm{b}} \pm 0.01$ \\
selenium & $2.35^{\mathrm{d}} \pm 0.05$ & $175.93^{\mathrm{a}} \pm 0.12$ & $148.33^{\mathrm{b}} \pm 0.58$ & $129.37^{\mathrm{c}} \pm 0.06$ \\
cobalt & $0.003^{\mathrm{b}} \pm 0.0$ & $0.003^{\mathrm{b}} \pm 0.0$ & $0.003^{\mathrm{b}} \pm 0.0$ & $0.003^{\mathrm{b}} \pm 0.0$ \\
lead & $0.12^{\mathrm{c}} \pm 0.01$ & $0.19^{\mathrm{a}} \pm 0.0$ & $0.13^{\mathrm{c}} \pm 0.01$ & $0.13^{\mathrm{c}} \pm 0.01$ \\
pH & $0.04^{\mathrm{b}} \pm 0.01$ & $0.06^{\mathrm{a}} \pm 0.00$ & $0.03^{\mathrm{c}} \pm 0.01$ & $0.03^{\mathrm{c}} \pm 0.00$ \\
\hline
\end{tabular}

All superscripts (a, b, c, and d) with different alphabet within the same row are significantly $(\mathrm{P}<0.05)$ different. Each sample was analysed in triplicate 
Table.2: Anti-nutritional factors of mineral salt licks produced using different binding agents.

\begin{tabular}{llllc}
\hline \multirow{2}{*}{ Parameters } & \multicolumn{1}{c}{ Treatment } & \multicolumn{4}{c}{$\mathbf{3}$} & \multicolumn{1}{c}{$\mathbf{4}$} \\
\cline { 2 - 5 } \multicolumn{1}{c}{$\mathbf{1}$} & \multicolumn{1}{c}{$\mathbf{2}$} & $0.59^{\mathrm{b}} \pm 0.02$ & $0.37^{\mathrm{c}} \pm 0.52$ \\
Tannin & $0.33^{\mathrm{c}} \pm 0.02$ & $1.24^{\mathrm{a}} \pm 0.02$ & $0.38^{\mathrm{b}} \pm 0.02$ & $0.22^{\mathrm{c}} \pm 0.02$ \\
Oxalate & $0.22^{\mathrm{c}} \pm 0.02$ & $0.75^{\mathrm{a}} \pm 0.2$ & $2.26^{\mathrm{c}} \pm 0.10$ & $2.22^{\mathrm{c}} \pm 0.03$ \\
Phytate & $3.57^{\mathrm{a}} \pm 0.03$ & $2.90^{\mathrm{b}} \pm 0.03$ & $1.96^{\mathrm{b}} \pm 0.04$ & $0.47^{\mathrm{c}} \pm 0.03$ \\
Flavonoid & $0.18^{\mathrm{d}} \pm 0.02$ & $4.43^{\mathrm{a}} \pm 0.02$ & $4.59^{\mathrm{c}} \pm 0.12$ & $2.60^{\mathrm{d}} \pm 0.02$ \\
Saponin & $10.93^{\mathrm{a}} \pm 0.32$ & $6.97^{\mathrm{b}} \pm 0.12$ & $3.77^{\mathrm{b}} \pm 0.22$ & $3.73^{\mathrm{b}} \pm 0.02$ \\
Alkaloid & $8.33^{\mathrm{a}} \pm 0.34$ & $3.04^{\mathrm{b}} \pm 0.12$ & $4.96^{\mathrm{c}} \pm 0.02$ & $4.24^{\mathrm{d}} \pm 0.02$ \\
\hline
\end{tabular}

All superscripts (a, b, c, d) with different alphabet within the same row are significantly $(\mathrm{P}<0.05)$ different.

TABLE 2 shows the anti-nutritional factors present in commercial salt lick and mineral salt licks produced using different binders. The composition of tannin, phenol and

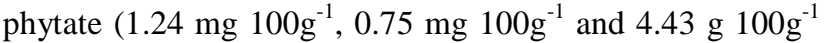
respectively) were increased significantly $(\mathrm{p}<0.05)$ in treatment 2 ( termite mound, bone meal and salt), while commercial salt lick (treatment 1) had lowest values of

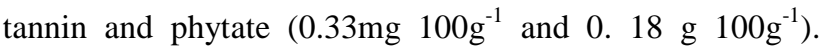

Flavonoids, saponin and alkaloid were significantly higher

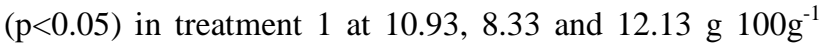
while treatment 4 recorded the lowest values of 2.60 and

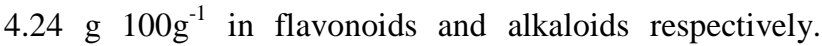
There were significant differences $(\mathrm{p}<0.05)$ among the

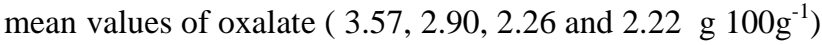
in treatments $1,2,3$ and 4 , respectively.

Table. 3: Hardness of mineral salt licks produced using different binding agents.

\begin{tabular}{lcccc}
\hline \multicolumn{1}{c}{ Drying time } & $\mathbf{1}$ & $\mathbf{2}$ & Treatment & $\mathbf{4}$ \\
\hline De-moulding & Good & Soft & Soft & Soft \\
One week & Good & Soft & Good & Soft \\
2 weeks & Good & Medium & Good & Medium \\
\hline
\end{tabular}

TABLE 3 depicts the degree of hardness of mineral salt blocks produced using different binders at the de-moulding stage, at one week and two weeks after production. The hardness of the control block was good all through. At demoulding, all the blocks in treatment 2 to 4 were soft when pressed with the hand. At one week, treatments 2 and 4 (blocks with termite mound and clay mud as binding agents, respectively) were soft, while treatment 3 (cement and bone meal) was good. At 2 weeks after moulding, treatment 3 showed good hardness while treatments 2 and 4 were of medium hardness.

Table.4: Compactness of mineral salt licks produced using different binding agents.

\begin{tabular}{lcccc}
\hline \multicolumn{1}{c}{ Drying time } & $\mathbf{1}$ & $\mathbf{2}$ & Treatment & $\mathbf{4}$ \\
\hline De-moulding & Firm & Loose & Loose & Loose \\
One week & Firm & Loose & Firm & Loose \\
2 weeks & Firm & Slightly loose & Firm & Slightly loose \\
\hline
\end{tabular}

The compactness of mineral salt blocks produced using different binders are shown in TABLE 4. The control block was firm in compactness. At de-moulding, all the mineral salts produced in treatment 2 to 4 were loose. At 1 week after production, treatments 2 and 4 were loose, while treatment 3 was firm. However, at 2 weeks after demoulding, treatment 3 with cement as binding agent was firm in compactness while treatments 2 and 4 (with termite mound and clay mud as binders, respectively) were slightly loose in compactness. 


\section{DISCUSSION}

The mineral salt licks produced using different binders had higher quality than commercial salt lick in terms of presence of mineral elements such as calcium, phosphorus, magnesium, zinc, iodine, chromium, copper, cobalt, and manganese. The variations in chemical compositions of the mineral licks were similar to the mineral contents of natural salt licks of the tropical rain forests $[8,17]$. This imply that locally manufactured mineral licks like natural lick sites may serve multiple functions as additional nutrient supply medium for different species and sexes of ruminants at different times of the year. This can supply the additional mineral sources that animals require such as calcium $(\mathrm{Ca})$, magnesium $(\mathrm{Mg})$, phosphorus $(\mathrm{P})$, potassium $(\mathrm{K})$, sodium $(\mathrm{Na})$, sulphur $(\mathrm{S})$, and chloride $(\mathrm{Cl})$ for the proper functioning of the animal body $[4,17]$. The commercial salt lick contains abundant sodium compared with the locally produced mineral salt lick. This is in line with the findings of Lameed andJenyo-Oni [17] that salt licks regularly visited by animals composed of primarily common salt. Results from analyses of some lick soils showing low sodium contents and the presence of other important elements such as magnesium [5], buffering compounds such as carbonates [6], and binding agents such as clays [7] suggest multiple uses of mineral licks. Studies also suggest that ruminants will naturally lick the mineral block when inclined, taking in iron from the red earth, calcium and phosphorus from termite mound, and iodine, sodium and chlorine from the salt $[6,18]$. These are all essential minerals necessary for the good health of ruminants especially cows and should result in the production of a good quantity of milk that is high in fat.

The proportion of the binding agents (14.3\%) in this study were similar to that of Sansoucy[19] who recommended the inclusion of $15 \%$ for a binding agent but higher than $4 \%$ of locust bean pulp used by Dzidiyaet al. [20], while the level of common salt used (28.6\%) was higher than $20 \%$ reported for multi-mineral block formulation [21]. Common salt serves as flavour and palatability enhancer and supplies sodium chloride which assist in consolidating the block and control the rate of ingestion. The high content of calcium in treatment 3 may be due to the use of cement as a binding agent in its production because cement contains appreciable amount of calcium [19].

The hardness of mineral blocks in which cement was used as the binder was good at 2 weeks. This is in line with the findings of Mubiet al. [22] who obtained good hardness at 2 weeks when Hassoun technique [23] was employed in multi-nutrient production using cement as binder. Blocks that set well ensure safe transportation without breakage [24]. However, according to Sancoucyet al. [9] andHadjipanayiotou[25], some formulations result in extremely hard blocks that could reduce block intake. Similar research result also revealed that hardness may reduce intake per visit and intake per lick in relation to solubility [26].

The $\mathrm{pH}$ obtained in this study fell within the range of 6.86 and 9.95 obtained by Matsubayashiet al. [8] and Onesmuset al.[27] on geophagic soil consumed by ruminants in tropical rain forests. The anti-nutritional factors of tannin, phytate and phenols in all the treatments were low and within tolerable levels. Anti-nutrititional factors even though are compounds which act to reduce nutrient utilization and/or food intake [28], have however found wide applications in nutrition as pharmacologically active agents. For example, saponins and flavonoids act as antioxidants, preservatives and flavouring agents in food and feed [29].

\section{CONCLUSION}

This study showed that it is possible to produce mineral salt blocks using locally available ingredients as binding agents. Termite mound and clay mud are of medium hardness and compactness containing appreciable amounts of macro and micro minerals. Termite mound as binder contains abundant minerals that can be useful to ruminants. Anti-nutrients in local ingredients used in this study were within tolerable limits.

\section{RECOMMENDATIONS}

From the results obtained in this study, locally sourced ingredients can serve as binders with medium hardness and compactness in mineral block formulations containing appreciable mineral contents. Termite mound and clay mud as binders are available in abundance and at no cost to resource poor ruminant farmers in Nigeria. Ruminant farmers are therefore advised to take initiative of producing mineral salt blocks locally. Further experiments in which mineral salt licks produced using local ingredients as binding agents as done in this present work should be fed to ruminants to ascertain their performance in comparison with commercial mineral salt licks.

\section{ACKNOWLEDGEMENT}

The author wishes to acknowledge Miss Oyewumi Nike for assisting in data collection for this manuscript. 


\section{REFERENCES}

[1] C. S Prasad, N. K. S Gowda, andJ. V Rammana.Feeding strategies to enhance animal productivity.In proceedings of the Xth Animal Nutrition conference. NDRI, Kamal, India.9-1 $1^{\text {th }}$ Nov 2001 Pp. 23-45

[2] A. K.Nagpal, and M. Arora..Utilization of Guar (Cyamopsistetragonolobus) phalgati and groundnut haulms based complete feeds in camel calves. Indian Journal of Animal Nutrition.2002.19: 69-72

[3] T. Smith .Salt- An essential element.Angus Journal.February 2008 Edition.177-179.

[4] L. R. McDowell,L. Recent advances in Minerals and Vitamins on Nutrition of Lactating Cows. Pakistan Journal of Nutrition.2002. 1(1): 8-19.

[5] W. E, Heimer. A magnesium-driven hypothesis of Dall sheep mineral lick use; preliminary tests and management relevance.Proc.BiennSymp North Wild Sheep Goat Council.1988. 6; 269-278

[6] D. A Kreulen."Lick use by large herbivores: A review of benefits and banes of soil consumption", Mammal Rev. 1985.15 (3): 107-123.

[7] G. Klaus andB. Schmid .Geophagy at natural licks and mammal ecology: a review. Mammalia.1998. 62:481-497

[8] H.Matsubayashi, M.Kitayama, P Lagan, N.Majalam, J. Tangah, J. R Abd. Sukor.Importance of natural licks for the mammals in Bornean Inland tropical rain forest.Ecological Research2006. doi10.1007/s111284006-0313-4

[9] R. Sancoucy, G. Aarts, and R. A. Leng. Urea-molasses blocks as a multinutrient supplement for ruminants.In Sugarcane as feed.FAO animal production and health paper. 1988. No 72. 263-269.

[10]H. Ben Salem, A. Nefzanou, andH. P. S. Makkar. Feed supplementation blocksfor increased utilization of tanniniferousfoliages by ruminants. In: FAO Technical paper 164. Feed supplementation blocks with urea- molasses multinutrient blocks: simple and effective feed supplementation technology for ruminant agriculture. FAO, Rome.2007 Pp. 185-205.

[11]A. A. Oshodi. Proximate composition, nutritionally valuable minerals and functional properties of Adenopusbreviflorusbenth seed flour and protein concentrate. Food Chem. 1992.45: 79 - 83.

[12]E. I. Wheeler, and R E Ferrel.A method for phytic acid determination in wheat fractions.Cereal Chem. $1971.48: 312-320$.

[13]H. P. S. Makkar, andA. V. Goodchild.Quantification of tannins, a laboratory manual.Int. Centre for Agric. Research 1996.128: 311 - 322.

[14]Z. Yan, O. Xing, and Zhi-Xian. Quantitative determination of oxalic acid using Victoria Blue B based on a catalytic Kinetic spectro photometric Microchemica. Acta. 2003. 144(1 -4): 199 - 205.

[15]B. O. Obadoni, andP. O. Ochuko. Phytochemical studies and comparative efficacy of the crude extracts of some homostatic plants in Edo and Delta States of Nigeria. Global Journal of Pure andAppli. Sc. 2001.8b: 203 - 208.

[16]J. B. Harbone. Phytochemical Methods. London. Chapman and Hall Ltd. 1973. Pp. 49 - 188.

[17]A. G. Lameed andO. A. Jenyo.Species- diversity utilization of salt lick sites at Borgu sector of Kainji Lake National Park, Nigeria. INTECH Publication.2012. 35-62.

[18] J. F. Dormaar, and B. D. Walker. Elemental content of animal licks along the eastern slopes of the Rocky mountains in southern Alberta, Canada. Canadian Journal of Soil Sciences. 1996. 76:509-512.

[19]R. Sancoucy. New Developments in the manufacture and utilization of multinutrient Blocks- short communication.

http//www.fao.org/DOCREP/v4440Tos.htm Dec, 2007.

[20] M. B. Dzidiya, I. H. Malgwi, H. DNyako, I. D Mohammed, M. M Yahya, and H. Y Abbaya.multi mineral block formulation and production using locally available feed ingredients in semi-arid region of Nigeria. Journal of Agric. And Vet. Science (IOSRJAVS).2015 Vol. 8, issue 7(11): 41-47.

[21]I. D. Mohammed M. Baulube and I. A. Adeyinka.Multinutrient blocks. 1. Formulation and production under a semi arid environment of Nigeria. Nigerian Journal of Biological Sciences.2007.7(2): 389-392.

[22]A. A. Mubi, A. Kibon and I. D. Mohammed.Formulation and production of multinutrient blocks for ruminants in the guinea savanna region of Nigeria.Agric and Biology Journal of North America. 2013. 4(3): 205-215.

[23]P. Hassoun. Manufacture of Urea blocks without mollasses. A monograph, FAO, Rome, Italy. 1989.

[24] M. Chemost, and C. Kayouli. Fabrication methods and guide for using multi-nutrient blocks. In: Roughage utilization in warm climates. FAO of the United Nations, Rome, Italy. 1997. Pp: 2-10.

[25] M. Hadijipanayiotu.(1996). Performance of Friesian 
Heifers on urea blocks and of Chios Ewes on blocks and other supplements.Livestock Research for Rural Development.1996. 8 (4): 1-8.

[26]M. A. McCoy, D. A. Rice, A Wright, D. G. Kennedy.(1994).Use of time-lapse video equipment to determine the efficacy of and palatability of commercial magnesium blocks in cattle.Vet. Rec.1994.135: 209-210.

[27]M. N. Onesmus, M. M. Levi, and O. O. Ochieng.Determination of Essential Minerals and Toxic Elements Composition of the Natural Licks Consumed By Livestock in Tharaka-Nithi County, Kenya.IOSR Journal of Agriculture and Veterinary Science: 2015. 8(10Ver.1): 45-53.

[28]A. U. Osagie.Antinutritional factors. In: nutritional quality plant foods. Ambik Press Ltd, Benin city, Nigeria. 1998. 221-244.

[29] J. You, X. Wang Y. Yan, F. Jin, and B. Huang.Effects of active constituents of Chinese herbal medicine on HMG-COA reductase. chemical Abs.1993. 120(7) $: 70$. 